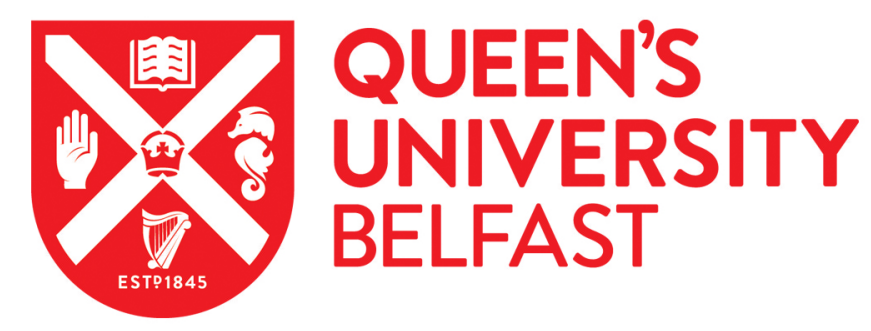

\title{
Symptoms and Endoscopic Features at Barrett's Esophagus Diagnosis: Implications for Neoplastic Progression Risk
}

Coleman, H. G., Bhat, S. K., Murray, L. J., McManus, D. T., O'Neill, O. M., Gavin, A. T., \& Johnston, B. T.
(2014). Symptoms and Endoscopic Features at Barrett's Esophagus Diagnosis: Implications for Neoplastic
Progression Risk. The American Journal of Gastroenterology, 109(4), 527-534. https://doi.org/10.1038/ajg.2014.10

Published in:

The American Journal of Gastroenterology

Document Version:

Peer reviewed version

Queen's University Belfast - Research Portal:

Link to publication record in Queen's University Belfast Research Portal

Publisher rights

( 2014 by the American College of Gastroenterology

\section{General rights}

Copyright for the publications made accessible via the Queen's University Belfast Research Portal is retained by the author(s) and / or other copyright owners and it is a condition of accessing these publications that users recognise and abide by the legal requirements associated with these rights.

Take down policy

The Research Portal is Queen's institutional repository that provides access to Queen's research output. Every effort has been made to ensure that content in the Research Portal does not infringe any person's rights, or applicable UK laws. If you discover content in the Research Portal that you believe breaches copyright or violates any law, please contact openaccess@qub.ac.uk. 
Original Research - Esophagus

Symptoms and endoscopic features at Barrett's esophagus diagnosis: implications for neoplastic progression risk

Short title: Endoscopic features and Barrett's progression risk

Authors: Helen G Coleman ${ }^{1 *}$, Shivaram K Bhat ${ }^{1 *}$, Liam J Murray ${ }^{1}$, Damian T McManus ${ }^{2}$, Orla M O’Neill ${ }^{1}$, Anna T Gavin ${ }^{3}$ and Brian T Johnston ${ }^{2}$.

\section{Affiliations:}

${ }^{1}$ Cancer Epidemiology \& Health Services Research Group, Centre for Public Health, Queen's University Belfast, Northern Ireland.

${ }^{2}$ Belfast Health \& Social Care Trust, Belfast, Northern Ireland.

${ }^{3}$ Northern Ireland Cancer Registry, Centre for Public Health, Queen's University Belfast, Northern Ireland

*These authors contributed equally to this work.

Correspondence to: Dr Helen Coleman. ICS-B Building, RVH Site, Grosvenor Road, Belfast, BT12 6BA, Northern Ireland. E-mail: h.coleman@qub.ac.uk; Tel +0044 (0) 2890635049; Fax: +0044 (0) 2890235900.

Word Count: 2,904

Key Words: Barrett's esophagus, esophageal adenocarcinoma, reflux, ulceration, risk factors. 


\section{STUDY HIGHLIGHTS}

\section{WHAT IS CURRENT KNOWLEDGE}

- A minority of Barrett's esophagus patients will undergo neoplastic progression

- Few factors have been identified that distinguish Barrett's esophagus patients at highest risk of progression

\section{WHAT IS NEW HERE}

- No short-segment Barrett's cases developed esophageal adenocarcinoma during the study period

- Ulceration in the Barrett's segment was associated with an increased risk of neoplastic progression

- Absence of reflux symptoms is not associated with a reduced risk of malignant progression 


\begin{abstract}
Introduction: Risk stratification of Barrett's esophagus (BE) patients based on clinical and endoscopic features may help to optimise surveillance practice for esophageal adenocarcinoma (EAC) development. The aim of this study was to investigate patient symptoms and endoscopic features at index endoscopy and risk of neoplastic progression in a large population-based cohort of BE patients.
\end{abstract}

Methods: A retrospective review of hospital records relating to incident BE diagnosis was conducted in a subset of patients with specialised intestinal metaplasia from the Northern Ireland $\mathrm{BE}$ register. Patients were matched to the Northern Ireland Cancer Registry to identify progressors to EAC or esophageal high grade dysplasia (HGD). Cox proportional hazards models were applied to evaluate the association between endoscopic features, symptoms and neoplastic progression risk.

Results: During 27,997 person-years of follow-up, 128 of 3,148 BE patients progressed to develop HGD/EAC. Ulceration within the Barrett's segment, but not elsewhere in the esophagus, was associated with an increased risk of progression (HR 1.72; 95\%CI: 1.08-2.76). Long segment BE carried a significant 7-fold increased risk of progression compared with short segment BE; none of the latter group developed EAC during the study period. A reported weight loss of $\geq 5 \mathrm{~kg}$ at incident $\mathrm{BE}$ was predictive of a doubled risk of progression to cancer, even up to 5 years post-diagnosis. Conversely, the absence of reflux symptoms was associated with a increased risk of cancer progression (HR 1.61; 95\% CI: 1.05-2.46).

Conclusions: BE patients presenting with a long segment BE, Barrett's ulcer or substantial weight loss have an increased risk of progressing to HGD/EAC and should be considered for more intense surveillance. The absence of reflux symptoms at BE diagnosis is not associated with a reduced risk of malignant progression, and may carry an increased risk of progression. 


\section{Introduction}

Barrett's esophagus (BE), metaplasia of the normal esophageal squamous epithelium into specialised columnar epithelium, is rising in incidence (over and above endoscopy rates) throughout the Western world.(1-3) The importance of BE lies in the fact that it is a precursor of esophageal adenocarcinoma (EAC), a tumor that has a poor prognosis. $(4,5)$ The opportunity for detection of $\mathrm{BE}$, and potential prevention of adenocarcinoma, has led gastroenterology organisations worldwide to endorse endoscopic surveillance of BE patients. $(6,7)$ However, endoscopic surveillance of $\mathrm{BE}$ is controversial due to ongoing debate as to its cost effectiveness.(8) Identifying patients at greatest risk of neoplastic progression, which only occurs in a minority of cases,(9-11) is a key priority in order to optimise the usefulness of such surveillance programmes.

$\mathrm{BE}$ and $\mathrm{EAC}$ are both thought to result from repeated exposure to bile and gastric acid in the distal esophagus.(12) A landmark publication from a Swedish population-based case-control study demonstrated that individuals reporting weekly reflux symptoms were at a 7 -fold increased risk of EAC.(13) Moreover, a dose-response relationship with frequency of symptoms was also noted.(13) However, in contrast to the link between symptoms in the general population and development of EAC, the relationship between reflux symptoms experienced at presentation of $\mathrm{BE}$ and subsequent risk of neoplastic progression is less certain.(14)

$\mathrm{BE}$ is thought to represent an adaptive response to acid-induced injury and ulceration and therefore it is not unexpected that a substantial proportion of $\mathrm{BE}$ patients purport to be 
asymptomatic.(15) The relevance of reflux, and other, symptoms present BE at diagnosis for stratification of cancer risk and associated need for surveillance is yet to be determined. Stratification of patients for surveillance based on other endoscopic findings at $\mathrm{BE}$ presentation, such as esophagitis and ulceration, has also been suggested by some studies.(14, 16) However, previous studies seeking to explore the association between these findings and EAC risk in a sequential manner have been limited by relatively small numbers of outcomes or lack of adjustment for known confounders, such as the presence of low grade dysplasia.(14, 16)

The aim of this study was to examine the association between symptoms and endoscopic features in incident BE patients and their risk of neoplastic progression in a large population based cohort. 


\section{Methods}

Data collection

BE patients with specialised intestinal metaplasia (SIM) were identified from the Northern Ireland $\mathrm{BE}$ register, which is a population-based register of all individuals aged $\geq 16$ years who were diagnosed with columnar-lined epithelium of the esophagus since 1993 in the province.(1) The register excludes BE cases with prevalent HGD, but retains those with indefinite or lowgrade dysplasia at incident BE diagnosis. Between 1993 and 2005, 4,717 BE patients were diagnosed with SIM, of whom 3,167 (comparable in age and sex distribution to all SIM patients) underwent a hospital case note review. The hospital notes of these patients were retrospectively reviewed by one of three trained data abstractors between March 2005 and March 2010. A standardised electronic proforma in Microsoft Access was utilised to extract demographic, medical, symptom, treatment and clinical information from records corresponding to the patient's incident diagnosis of BE. The process of this case note review has been previously described for outcomes up to the end of 2008.(17) The Northern Ireland $\mathrm{BE}$ register has subsequently been populated with the Health and Social Care number (a unique identifier within the UK National Health Service). This allowed identification of a small number of duplicate patients ( $\mathrm{n}=19,0.6 \%$ ), leaving 3,148 BE patients in the current analysis.

Confirmation of outcome diagnosis

Details of the linkage process and confirmation of BE patients who progressed to develop cancer and high grade dysplasia (HGD) in this cohort have been published elsewhere.(9) Briefly, the Northern Ireland BE register was linked to the Northern Ireland Cancer Registry to identify patients diagnosed with incident esophageal and gastric cardia adenocarcinomas or unspecified cancers of the esophagus on or before $31^{\text {st }}$ December 2010. Esophageal squamous 
cell carcinomas were excluded. Cases of HGD were identified from an electronic and manual review of all esophageal biopsy reports within Northern Ireland up to $31^{\text {st }}$ December 2010. Only cancers or HGD diagnosed at least six months after an incident BE diagnosis were included, to minimise the potential for prevalent cancers to have influenced symptom experience and endoscopic features. The Northern Ireland BE register was matched to the General Registrar's Office in Northern Ireland to identify deaths occurring over the same time period.

Statistical analysis

Independent $t$-tests and chi-squared tests were applied to compare continuous and categorical variables, respectively, between BE patients who progressed to cancer or HGD and those who did not progress. Where the report relating to an incident $\mathrm{BE}$ diagnosis did not mention a symptom or endoscopic feature, for example gastrointestinal bleeding, that patient was presumed to not have experienced that symptom or feature and was recoded accordingly. Cox proportional hazards models were applied to investigate the association between reported symptoms and endoscopic features at incident BE diagnosis and the risk of progression to cancer or HGD. Assumptions for Cox proportional hazards models were checked by visual inspection of Kaplan Meier plots. Both unadjusted and adjusted models were applied, using a censor date as the date of death, date of cancer or HGD diagnosis or $31^{\text {st }}$ December 2010. In adjusted models, included confounders were age, sex, presence of low-grade dysplasia, socioeconomic status (reflected by area-based income deprivation quintiles), tobacco smoking status (never/former/current/unknown) and Barrett's segment length, based on a priori knowledge of these risk factors for EAC development. We also tested adjustment for ever use of medications including non-steroidal anti-inflammatory drugs (NSAIDs), aspirin, proton pump inhibitors 
(PPIs) and $\mathrm{H} 2$ antagonists but these did not significantly alter the results shown. Stratified analyses were conducted for cancer only outcomes by follow-up duration, age categories, Barrett's segment length, smoking status, PPI usage and dysplastic status. Tests for interactions were conducted using the likelihood ratio test. In addition, sensitivity analyses excluding outcomes diagnosed within one year of follow-up were conducted to minimise the likelihood of reverse causation from undetected prevalent neoplasms. All statistical analysis was conducted using Intercooled Stata Version 11 (StataCorp, Texas, USA). 


\section{Results}

A total of 3,148 BE patients were followed for a mean $( \pm \mathrm{SD})$ of $8.9( \pm 4.1)$ years (range 0.5 18.0 years). During this period, 128 patients progressed to develop HGD $(n=36)$ or EAC $(n=92)$. Demographic, lifestyle and clinical data of these patients are displayed in Table 1. Progressors were more likely to be male, aged 60-70 years at incident BE, have long-segment BE, low-grade dysplasia and have ever smoked tobacco compared with non-progressors. No significant differences were observed between progressors and non-progressors in terms of socio-economic status or usage of certain medications (NSAIDs, aspirin, H2 antagonists or PPIs) at their incident BE diagnosis.

Table 2 outlines the association between esophageal features noted at endoscopy and the risk of neoplastic progression in incident BE. Long segment Barrett's was associated with a sevenfold increased risk of progression, although segment length was unknown in approximately half of patients. Only two patients with short-segment BE progressed to HGD, with none developing EAC during the study time period. Progressors were more likely to have had a Barrett's ulcer at their incident diagnosis compared with non-progressors (HR 1.99; 95\% CI: 1.26-3.15), even after adjustment for confounders (HR 1.72; 95\% CI: 1.08-2.76). Other endoscopic features, including esophagitis, esophageal stricture, and presence of hiatus hernia, were unrelated to progression risk. Largely similar results were observed in analysis including only cancer progressors (Table 2).

The association between reported symptoms at incident BE diagnoses and the risk of progression is shown in Table 3. Incident BE patients reporting gastro-esophageal reflux symptoms had a reduced risk of cancer progression (HR 0.62; 95\% CI: 0.41-0.95). This was 
equivalent to asymptomatic patients having a $61 \%$ increased risk of EAC progression, after adjustment for confounders (HR 1.61; 95\% CI: 1.05-2.46). The association was weaker when considering HGD and EAC outcomes combined. BE patients reporting $\geq 5 \mathrm{~kg}$ loss in body weight at their incident diagnosis were at a significantly increased risk of cancer progression (HR 2.01; 95\% CI: 1.01-3.98) compared with patients who did not report experiencing weight loss. No other reported symptoms were associated with progression risk.

\section{A priori sensitivity and stratified analyses}

As shown in Supplementary Figure 1, the magnitude of the inverse association between reflux symptoms and EAC progression risk remained consistent across strata of follow-up time, age categories, BE segment length, smoking status, PPI usage and in non-dysplastic BE at index diagnosis. Small numbers precluded meaningful sensitivity and stratified analyses for weight loss and Barrett's ulceration findings. Nevertheless, it should be noted that the direct association between a reported weight loss of $\geq 5 \mathrm{~kg}$ and cancer progression remained even up to five years post-incident BE diagnosis (HR 3.09; 95\% CI: 1.27-7.53).

All previously observed associations remained largely unaltered in sensitivity analyses of patients whose esophageal HGD or cancer was diagnosed at least one year after their incident BE diagnosis (Table 4). 


\section{Discussion}

In the present study, based on one of the largest series of progressors from BE to HGD/EAC in the world, the presence of long-segment Barrett's carried a seven-fold increased risk of progression. Smaller, but statistically significant, increased risks of progression were also noted for patients with Barrett's ulceration and for those reporting substantial weight loss at their incident diagnosis. Gastro-esophageal reflux symptoms were associated with a decreased risk of cancer progression, while no other reported symptoms or endoscopic findings were predictive of progression in these patients.

Due to the relatively low proportion of BE patients who progress to HGD/EAC,(9) research efforts are attempting to identify factors that may streamline the entry into surveillance and its frequency. The relevance of both symptoms at presentation and endoscopic findings at BE diagnosis are of importance to clinicians when considering entry into surveillance and risk of malignant progression with individual patients.(18)

A study of $27 \mathrm{BE}$ patients undergoing 24 hour esophageal $\mathrm{pH}$ monitoring has previously identified a strong positive correlation between the duration of acid exposure and Barrett's segment length.(19) One of the key findings from the current study was that patients with long segment $\mathrm{BE}$ (defined as $\geq 3 \mathrm{~cm}$ ) had a seven-fold increased risk of progression to $\mathrm{HGD} / \mathrm{EAC}$ compared with short segment Barrett's. Our analysis was somewhat limited though, since Barrett's segment length was unknown in almost half of patients. The finding that longer segment length corresponds to increased progression risk concurs with results from several other studies(20-22) and previous reports from this cohort.(9) The lack of progression in short- 
segment BE cases suggests that there would be limited benefits to entering these patients into current surveillance protocols, and that longer surveillance intervals or additional criteria for inclusion in surveillance programs may be warranted.(23)

In addition, our findings demonstrated that the presence of Barrett's ulceration, but not ulceration elsewhere in the esophagus, increased the risk of progression to HGD/EAC. Because our study is large, it builds upon observations from previous smaller studies, affording greater specificity of findings. In an Australian study of $353 \mathrm{BE}$ patients, of whom 13 progressed to $\mathrm{HGD} / \mathrm{EAC}$ over a 20 year follow-up period, the combined presence of severe esophagitis, nodularity, Barrett's ulceration and/or stricture was deemed to elevate the risk of progression in age- and sex-adjusted analysis.(16) A small study reported by Switzer-Taylor et al (2008), in which 9 esophageal cancers were detected amongst a sample of 212 BE patients during 13 years of follow-up, noted that half of progressors had ulceration at their index endoscopy.(24) A Dutch study of 713 patients, incorporating 26 progressors, found BE 'irregularities' (incorporating erosions, ulcers and nodules) to carry a non-significant 2-fold increased risk of progression in multivariate models, while esophagitis was a determinant of progression.(14) A recent report from the North-Eastern Italian BE register also noted ulceration or nodularity to be associated with a heightened risk of HGD/EAC in analysis of 22 progressors.(25)

Case-control studies have identified that reflux symptoms in the general population are linked with esophageal carcinogenesis.(12, 26, 27) That is consistent with the well-established role of reflux in BE development. $(28,29)$ By contrast, asymptomatic BE patients in the current study were found to be at greater risk of EAC progression, and whom a recent review 
highlighted to have an unknown prognosis.(30) In turn, these findings point to the presence of reflux symptoms at the time of diagnosis of BE diagnosis as being inversely associated with progression risk. It is highly unlikely that this reflects a 'true' decreased risk, since mechanistic evidence supports the carcinogenic effects of chronic acid exposure in Barrett's cell lines, such as inflammation and induction of chromosomal aneuploidy,(31) which is predictive of BE progression risk.(32)

Rather, it is more plausible that a poor correlation exists between patient perception of reflux and actual refluxate in the esophagus. Symptoms of gastro-esophageal reflux disease are not predictive of BE presence,(33) and it has long been known that there is reduced esophageal acid sensitivity in columnar versus squamous mucosa.(34) A small pain-stimulation study has also demonstrated that $\mathrm{BE}$ patients are hyposensitive to heat in both the normal squamous and the metaplastic epithelium of their esophagus compared with normal controls,(35) hence may be less likely to report symptoms. Our results suggested this was not reflective of age disparities in symptom recognition, as has been postulated by others.(36, 37) The relationship between symptoms and acid exposure is an important area for further research, since our findings suggest that subjectively reported symptoms would not be useful in stratifying highrisk $\mathrm{BE}$ patients for surveillance. Moreover, our results also raise questions over symptom control being the desired endpoint in BE management, as has been highlighted by Sarela and colleagues.(38) Asymptomatic patients may still require anti-acid treatments.

In addition, we observed that weight loss of $\geq 5 \mathrm{~kg}$ in $\mathrm{BE}$ patients was associated with a significantly increased risk of progression. It is unlikely that such weight loss was reflecting subclinical disease, or the development of more aggressive tumors amongst BE progressors, 
since progression risk remained elevated up to five years after BE diagnosis. Such substantial weight loss could reflect prior overweight/obesity, which is a known risk factor for esophageal adenocarcinoma. $(12,39)$ It is important for future prospective studies to distinguish the intent, nature and timing of weight loss. This is necessary to avoid detracting from the public health message that individuals should maintain a normal body weight in order to reduce their risk of developing EAC. $(39,40)$

Our study has several strengths, including its large size and population-based setting in the Northern Ireland $\mathrm{BE}$ register, providing generalisability to all $\mathrm{BE}$ patients in the province. Although information was collected retrospectively, it was retrieved from hospital case notes relating to a patient's incident BE diagnosis. Therefore, this is the largest study to date that has investigated endoscopic findings and symptom experiences and progression risk in a sequential manner. In addition, we were able to control for a number of known confounders in our analysis.

There are some limitations to our analysis. It is possible that some patients did not report all of their symptoms to clinicians in order for them to be recorded in the case notes. The potentially subjective nature of symptoms reporting means that results for reflux symptoms and weight loss should be interpreted with caution. Our analysis of Barrett's segment length was relatively crude as we did not have exact length in $\mathrm{cm}$ for most patients and length was unknown for a considerable proportion. It is also plausible that there may be some residual confounding from unaccounted variables in our analysis. 
In conclusion, BE patients presenting with long segment Barrett's, Barrett's ulceration or substantial weight loss have an increased risk of progressing to HGD/EAC and should be considered for more intense surveillance. The absence of reflux symptoms at diagnosis is not associated with a reduced risk of malignant progression, and may carry an increased risk of progression. 


\section{References}

1. Coleman HG, Bhat S, Murray LJ et al. Increasing incidence of Barrett's oesophagus: a population-based study. Eur J Epidemiol 2011;26:739-45.

2. Post PN, Siersema PD, Van Dekken H. Rising incidence of clinically evident Barrett's oesophagus in The Netherlands: a nation-wide registry of pathology reports. Scand J Gastroenterol 2007;42:17-22.

3. van Soest EM, Dieleman JP, Siersema PD et al. Increasing incidence of Barrett's oesophagus in the general population. Gut 2005;54:1062-6.

4. Eloubeidi MA, Mason AC, Desmond RA et al. Temporal trends (1973-1997) in survival of patients with esophageal adenocarcinoma in the United States: a glimmer of hope? Am J Gastroenterol 2003;98:1627-33.

5. Mitry E, Rachet B, Quinn MJ et al. Survival from cancer of the oesophagus in England and Wales up to 2001. Br J Cancer 2008;99 Suppl 1:S11-3.

6. British Society of Gastroenterology. Guidelines for the diagnosis and management of Barrett's columnar-lined oesophagus 2005;28.

7. Wang KK, Sampliner RE, Practice Parameters Committee of the American College of Gastroenterology. Updated guidelines 2008 for the diagnosis, surveillance and therapy of Barrett's esophagus. Am J Gastroenterol 2008;103:788-97.

8. Hirst NG, Gordon LG, Whiteman DC et al. Is endoscopic surveillance for non-dysplastic Barrett's esophagus cost-effective? Review of economic evaluations. J Gastroenterol Hepatol 2011;26:247-54. 
9. Bhat S, Coleman HG, Yousef F et al. Risk of malignant progression in Barrett's esophagus patients: results from a large population-based study. J Natl Cancer Inst 2011;103:1049-57.

10. Yousef F, Cardwell C, Cantwell MM et al. The incidence of esophageal cancer and highgrade dysplasia in Barrett's esophagus: a systematic review and meta-analysis. Am J Epidemiol 2008;168:237-49.

11. Hvid-Jensen F, Pedersen L, Drewes AM et al. Incidence of adenocarcinoma among patients with Barrett's esophagus. N Engl J Med 2011;365:1375-83.

12. Anderson LA, Watson RG, Murphy SJ et al. Risk factors for Barrett's oesophagus and oesophageal adenocarcinoma: results from the FINBAR study. World J Gastroenterol 2007;13:1585-94.

13. Lagergren J, Bergstrom R, Lindgren A et al. Symptomatic gastroesophageal reflux as a risk factor for esophageal adenocarcinoma. N Engl J Med 1999;340:825-31.

14. Sikkema M, Looman CW, Steyerberg EW et al. Predictors for Neoplastic Progression in Patients With Barrett's Esophagus: A Prospective Cohort Study. Am J Gastroenterol 2011; 106(7):1231-8.

15. Fitzgerald RC. Review article: Barrett's oesophagus and associated adenocarcinoma--a UK perspective. Aliment Pharmacol Ther 2004;20 Suppl 8:45-9.

16. Hillman LC, Chiragakis L, Clarke AC et al. Barrett's esophagus: Macroscopic markers and the prediction of dysplasia and adenocarcinoma. J Gastroenterol Hepatol 2003;18:52633. 
17. Coleman HG, Bhat S, Johnston BT et al. Tobacco smoking increases the risk of highgrade dysplasia and cancer among patients with Barrett's esophagus. Gastroenterology 2012;142:233-40.

18. Prasad GA, Bansal A, Sharma P et al. Predictors of progression in Barrett's esophagus: current knowledge and future directions. Am J Gastroenterol 2010;105:1490-502.

19. Fass R, Hell RW, Garewal HS et al. Correlation of oesophageal acid exposure with Barrett's oesophagus length. Gut 2001;48:310-3.

20. Iftikhar SY, James PD, Steele RJ et al. Length of Barrett's oesophagus: an important factor in the development of dysplasia and adenocarcinoma. Gut 1992;33:1155-8.

21. O'Connor JB, Falk GW, Richter JE. The incidence of adenocarcinoma and dysplasia in Barrett's esophagus: report on the Cleveland Clinic Barrett's Esophagus Registry. Am J Gastroenterol 1999;94:2037-42.

22. Weston AP, Badr AS, Hassanein RS. Prospective multivariate analysis of clinical, endoscopic, and histological factors predictive of the development of Barrett's multifocal high-grade dysplasia or adenocarcinoma. Am J Gastroenterol 1999;94:3413-9.

23. Desai TK, Krishnan K, Samala N et al. The incidence of oesophageal adenocarcinoma in non-dysplastic Barrett's oesophagus: a meta-analysis. Gut 2012;61:970-6.

24. Switzer-Taylor V, Schlup M, Lubcke R et al. Barrett's esophagus: a retrospective analysis of 13 years surveillance. J Gastroenterol Hepatol 2008;23:1362-7. 
25. Rugge M, Zaninotto G, Parente P et al. Barrett's esophagus and adenocarcinoma risk: the experience of the North-Eastern Italian Registry (EBRA). Ann Surg 2012;256:788,94; discussion 794-5.

26. Avidan B, Sonnenberg A, Schnell TG et al. Hiatal hernia size, Barrett's length, and severity of acid reflux are all risk factors for esophageal adenocarcinoma. Am J Gastroenterol 2002;97:1930-6.

27. Stapley S, Peters TJ, Neal RD et al. The risk of oesophago-gastric cancer in symptomatic patients in primary care: a large case-control study using electronic records. Br J Cancer 2013;108:25-31.

28. Westhoff B, Brotze S, Weston A et al. The frequency of Barrett's esophagus in high-risk patients with chronic GERD. Gastrointest Endosc 2005;61:226-31.

29. Oberg S, Ritter MP, Crookes PF et al. Gastroesophageal reflux disease and mucosal injury with emphasis on short-segment Barrett's esophagus and duodenogastroesophageal reflux. J Gastrointest Surg 1998;2:547,53; discussion 553-4.

30. Lenglinger J, Riegler M, Cosentini E et al. Review on the annual cancer risk of Barrett's esophagus in persons with symptoms of gastroesophageal reflux disease. Anticancer Res 2012;32:5465-73.

31. Bajpai M, Aviv H, Das KM. Prolonged exposure to acid and bile induces chromosome abnormalities that precede malignant transformation of benign Barrett's epithelium. Mol Cytogenet 2012;5:43,8166-5-43. 
32. Bird-Lieberman EL, Dunn JM, Coleman HG et al. Population-based study reveals new risk-stratification biomarker panel for Barrett's esophagus. Gastroenterology 2012;143:927,35.e3.

33. Ward EM, Wolfsen HC, Achem SR et al. Barrett's esophagus is common in older men and women undergoing screening colonoscopy regardless of reflux symptoms. Am J Gastroenterol 2006;101:12-7.

34. Johnson DA, Winters C, Spurling TJ et al. Esophageal acid sensitivity in Barrett's esophagus. J Clin Gastroenterol 1987;9:23-7.

35. Krarup AL, Olesen SS, Funch-Jensen P et al. Proximal and distal esophageal sensitivity is decreased in patients with Barrett's esophagus. World J Gastroenterol 2011;17:514-21.

36. Becher A, Dent J. Systematic review: ageing and gastro-oesophageal reflux disease symptoms, oesophageal function and reflux oesophagitis. Aliment Pharmacol Ther 2011;33:442-54.

37. Fass R, Pulliam G, Johnson C et al. Symptom severity and oesophageal chemosensitivity to acid in older and young patients with gastro-oesophageal reflux. Age Ageing 2000;29:12530.

38. Sarela AI, Verbeke CS, Pring C et al. Is symptom control the correct end point for proton pump inhibitor treatment in Barrett's oesophagus?. Gut 2004;53:1387-8.

39. Renehan AG, Tyson M, Egger M et al. Body-mass index and incidence of cancer: a systematic review and meta-analysis of prospective observational studies. Lancet 2008;371:569-78. 
40. Smith M, Zhou M, Whitlock G et al. Esophageal cancer and body mass index: results from a prospective study of 220,000 men in China and a meta-analysis of published studies. Int J Cancer 2008;122:1604-10. 


\section{Acknowledgements}

Gratitude is extended to the Tumor Verification Officers in the Northern Ireland Cancer Registry who collected the data presented in this report, namely Mrs Kate Donnelly, Mrs Rosemary Ward and Ms Olwyn Dawson. We would also like to acknowledge the input of all staff in the Centre for Public Health at Queen's University Belfast, past and present, who have contributed to the development of the Northern Ireland BE register. This study was supported by funding from Cancer Focus Northern Ireland (formerly the Ulster Cancer Foundation) and the Health and Social Care Research and Development Office, Northern Ireland. The Northern Ireland Cancer Registry is funded by the Public Health Agency for Northern Ireland.

\section{Conflict of Interest/Study Support}

Guarantor of the article: Professor Liam Murray

Specific author contributions: LM and BJ had the study concept; LM, BJ \& AG acquired funding for the Northern Ireland Barrett's register; LM, DM, OO’N, HC \& SB were responsible for the maintenance of the Northern Ireland Barrett's register; AG has overall responsibility for the Northern Ireland Cancer Registry; HC and SB conducted statistical analysis and co-wrote the first draft of the article; All authors contributed to the writing and editing of the final manuscript.

Financial support: This work was supported by funding from Cancer Focus Northern Ireland (formerly the Ulster Cancer Foundation) and the Health and Social Care Research and Development Office, Northern Ireland. HG Coleman is currently supported by a Cancer Research UK Population Research Postdoctoral Fellowship. The study sponsors did not have 
any role in the study design, collection, analysis or interpretation of data or the writing of the report.

Potential competing interests: None. 
Table 1. Descriptive characteristics of patients at their index Barrett's esophagus diagnosis.

\begin{tabular}{|c|c|c|c|}
\hline Characteristics & $\begin{array}{l}\text { Non- } \\
\text { progressors } \\
(n=3,023)\end{array}$ & $\begin{array}{l}\text { Progressors } \\
(n=128)\end{array}$ & $P$-value \\
\hline $\begin{array}{l}\text { Mean age at Barrett's diagnosis } \\
\text { (years) }\end{array}$ & $62.0 \pm 14.1$ & $62.1 \pm 11.5$ & 0.98 \\
\hline \multicolumn{4}{|l|}{ Age group (years) } \\
\hline $16-<40$ & $195 \quad(6.5)$ & $4 \quad(3.1)$ & \multirow{6}{*}{0.006} \\
\hline $40-<50$ & $432 \quad(14.3)$ & $14(10.9)$ & \\
\hline $50-<60$ & $681 \quad(22.5)$ & $31(24.2)$ & \\
\hline $60-<70$ & $753 \quad(24.9)$ & $49(38.3)$ & \\
\hline $70-<80$ & $643 \quad(21.3)$ & $24(18.8)$ & \\
\hline$\geq 80$ & $319 \quad(10.5)$ & $6 \quad(4.7)$ & \\
\hline \multicolumn{4}{|l|}{ Sex } \\
\hline Male & $1,881 \quad(62.2)$ & $99(77.3)$ & \multirow[t]{2}{*}{0.001} \\
\hline Female & $1,142(37.8)$ & $29(22.7)$ & \\
\hline \multicolumn{4}{|l|}{ Barrett's segment length } \\
\hline Short, $<3 \mathrm{~cm}$ & $323 \quad(10.7)$ & $2 \quad(1.6)$ & \multirow{3}{*}{0.001} \\
\hline Long, $\geq 3 \mathrm{~cm}$ & $1,316(43.5)$ & $71(55.5)$ & \\
\hline Unknown & $1,384(45.8)$ & $55(43.0)$ & \\
\hline \multicolumn{4}{|l|}{ Presence of dysplasia* } \\
\hline Yes & $182 \quad(6.0)$ & $31(24.2)$ & \multirow{3}{*}{$<0.001$} \\
\hline No & $2,602(86.1)$ & $83(64.8)$ & \\
\hline Unknown & $239 \quad(7.9)$ & $14(11.0)$ & \\
\hline \multicolumn{4}{|l|}{ Income deprivation quintile } \\
\hline I (Most deprived) & $(21.1)$ & $28(21.9)$ & \multirow{6}{*}{0.23} \\
\hline II & $(19.8)$ & $33(25.8)$ & \\
\hline III & $(17.6)$ & $22(17.2)$ & \\
\hline IV & $(17.2)$ & $14(10.9)$ & \\
\hline V (Least deprived) & $(15.2)$ & $23(18.0)$ & \\
\hline Unknown & $(9.1)$ & $8 \quad(6.2)$ & \\
\hline \multicolumn{4}{|l|}{ Smoking status } \\
\hline Never & $1,394(46.1)$ & $47(36.7)$ & \multirow{4}{*}{0.001} \\
\hline Former & $619 \quad(20.5)$ & $33(25.8)$ & \\
\hline Current & $(23.5)$ & $44(34.4)$ & \\
\hline Unknown & $(9.9)$ & $4 \quad(3.6)$ & \\
\hline \multicolumn{4}{|l|}{ Ever use of medications } \\
\hline NSAIDs & $(7.0)$ & $8 \quad(6.3)$ & 0.74 \\
\hline Aspirin & $(16.4)$ & $15(11.7)$ & 0.16 \\
\hline H2 Antagonists & $437 \quad(14.5)$ & $23(18.0)$ & 0.27 \\
\hline PPIs & $1,378(45.6)$ & $58(45.3)$ & 0.95 \\
\hline
\end{tabular}

*Low grade or indefinite dysplasia; NSAIDs: Non-steroidal anti-inflammatory drugs; H2 Antagonists; PPIs: Proton pump inhibitors. 
Table 2. Endoscopic features at incident BE diagnosis and risk of neoplastic progression.

\begin{tabular}{|c|c|c|c|c|c|c|c|c|c|c|}
\hline Risk factors & $\begin{array}{l}\text { Non- } \\
\text { progressors } \\
(n=3,020)\end{array}$ & $\begin{array}{l}\text { All } \\
\text { Progressors } \\
(n=128) \\
\end{array}$ & \multirow[t]{2}{*}{$\begin{array}{l}\text { Unadjusted } \\
\text { Hazard ratio } \\
(95 \% \mathrm{CI})\end{array}$} & \multirow[t]{2}{*}{$P$ trend } & \multirow[t]{2}{*}{$\begin{array}{l}\text { Adjusted } \\
\text { Hazard ratio } \\
(95 \% \text { CI })\end{array}$} & \multirow[t]{2}{*}{$P$ trend } & \multicolumn{2}{|c|}{$\begin{array}{l}\text { EAC } \\
\text { Progressors } \\
(n=92)\end{array}$} & \multirow[t]{2}{*}{$\begin{array}{l}\text { Adjusted } \\
\text { Hazard ratio } \\
(95 \% \mathrm{CI})\end{array}$} & \multirow[t]{2}{*}{$P$ trend } \\
\hline Length of Barre & & & & & & & & & & \\
\hline Short $(<3 \mathrm{~cm})$ & $323 \quad(10.7)$ & $2 \quad(1.5)$ & 1.00 & & 1.00 & & 0 & $(0.0)$ & / & / \\
\hline Long ( $\geq 3 \mathrm{~cm})$ & $1,314(43.5)$ & $71 \quad(55.5)$ & $8.24(2.02-33.58)$ & 0.004 & $7.10(1.74-29.04)$ & 0.003 & 53 & $(57.6)$ & & \\
\hline Unknown & $1,383(45.8)$ & $55 \quad(43.0)$ & $6.23(1.52-25.56)$ & & $5.82(1.42-23.94)$ & & 39 & $(42.4)$ & & \\
\hline \multicolumn{11}{|l|}{ Barrett's ulcer } \\
\hline No/unknown & $2,748(91.0)$ & $106(82.8)$ & 1.00 & & 1.00 & & 75 & $(81.5)$ & 1.00 & \\
\hline Yes & $272 \quad(9.0)$ & $22(17.2)$ & $1.99(1.26-3.15)$ & 0.003 & $1.72(1.08-2.76)$ & 0.02 & 17 & $(18.5)$ & $1.83(1.07-3.13)$ & 0.03 \\
\hline \multicolumn{11}{|l|}{ Esophagitis* } \\
\hline No/unknown & $1,760(58.3)$ & $83(64.8)$ & 1.00 & & 1.00 & & 56 & $(60.9)$ & 1.00 & \\
\hline Yes & $1,260(41.7)$ & $45 \quad(35.2)$ & $0.74(0.52-1.07)$ & 0.11 & $0.77(0.53-1.12)$ & 0.18 & 36 & $(39.1)$ & $0.97(0.63-1.49)$ & 0.88 \\
\hline \multicolumn{11}{|c|}{ Esophageal stricture seen } \\
\hline No/unknown & $2,811(93.1)$ & $115(89.8)$ & 1.00 & & 1.00 & & 83 & $(90.2)$ & 1.00 & \\
\hline Yes & $209 \quad(6.9)$ & $13(10.2)$ & $1.56(0.88-2.78)$ & 0.13 & $1.65(0.92-2.95)$ & 0.09 & 9 & $(9.8)$ & $1.59(0.79-3.21)$ & 0.19 \\
\hline \multicolumn{11}{|l|}{ Hiatus hernia } \\
\hline No/unknown & $1,283(42.5)$ & $56 \quad(43.8)$ & 1.00 & & 1.00 & & 41 & $(44.6)$ & 1.00 & \\
\hline Yes & $1,737(57.5)$ & $72 \quad(56.3)$ & $0.90(0.63-1.28)$ & 0.56 & $0.95(0.67-1.36)$ & 0.79 & 51 & $(55.4)$ & $0.92(0.60-1.39)$ & 0.68 \\
\hline
\end{tabular}

*Incorporates patients recorded as having esophagitis or ulceration in an area of the esophagus other than their Barrett's segment.

Adjustments: age groups (16- $<40 / 40-<50 / 50-<60 / 60-<70 / 70-<80 / \geq 80$ years), sex (male/female), presence of low grade dysplasia (yes/no/unknown), income deprivation quintile (I/II/III/IV/V/unknown), Barrett's segment length (long/short or unknown) (except Length of Barrett's analysis), smoking status (never/former/current/unknown). 
Table 3. Reported symptoms at incident BE diagnosis and risk of neoplastic progression.

\begin{tabular}{|c|c|c|c|c|c|c|c|c|c|}
\hline Risk factors & $\begin{array}{l}\text { Non- } \\
\text { progressors } \\
(n=3,020)\end{array}$ & $\begin{array}{l}\text { All } \\
\text { Progressors } \\
(n=128) \\
\end{array}$ & $\begin{array}{l}\text { Unadjusted } \\
\text { Hazard ratio } \\
(95 \% \mathrm{CI})\end{array}$ & $P$ trend & $\begin{array}{l}\text { Adjusted } \\
\text { Hazard ratio } \\
(95 \% \mathrm{CI})\end{array}$ & $P$ trend & $\begin{array}{l}\text { EAC } \\
\text { Progressors } \\
(n=92)\end{array}$ & $\begin{array}{l}\text { Adjusted } \\
\text { Hazard ratio } \\
(95 \% \mathrm{CI})\end{array}$ & $P$ trend \\
\hline \multicolumn{10}{|l|}{ Presence of reflux } \\
\hline No/unknown & $1,392(46.1)$ & $57(44.5)$ & 1.00 & & 1.00 & & $45(48.9)$ & 1.00 & \\
\hline Yes & $1,628(53.9)$ & $71(55.5)$ & $0.85(0.60-1.21)$ & 0.36 & $0.76(0.53-1.09)$ & 0.13 & $47(51.1)$ & $0.62(0.41-0.95)$ & 0.03 \\
\hline \multicolumn{10}{|l|}{ GI bleeding } \\
\hline No/unknown & $2,652(87.8)$ & $115(89.8)$ & 1.00 & & 1.00 & & $80 \quad(87.0)$ & 1.00 & \\
\hline Yes & $368 \quad(12.2)$ & $13(10.2)$ & $0.97(0.54-1.72)$ & 0.91 & $0.95(0.54-1.70)$ & 0.88 & $12(13.0)$ & $1.26(0.68-2.34)$ & 0.46 \\
\hline \multicolumn{10}{|l|}{ Anaemia } \\
\hline No/unknown & $2,630(87.1)$ & $112(87.5)$ & 1.00 & & 1.00 & & $78 \quad(84.8)$ & 1.00 & \\
\hline Yes & $390 \quad(12.9)$ & $16(12.5)$ & $1.14(0.67-1.92)$ & 0.63 & $1.25(0.72-2.14)$ & 0.43 & $14 \quad(15.2)$ & $1.45(0.80-2.64)$ & 0.22 \\
\hline \multicolumn{10}{|l|}{ Dysphagia } \\
\hline No/unknown & $2,357(78.0)$ & $97 \quad(75.8)$ & 1.00 & & 1.00 & & $70 \quad(76.5)$ & 1.00 & \\
\hline Yes & $663 \quad(22.0)$ & $31 \quad(24.2)$ & $1.10(0.74-1.65)$ & 0.64 & $1.21(0.80-1.82)$ & 0.36 & $22 \quad(23.5)$ & $1.20(0.74-1.95)$ & 0.45 \\
\hline \multicolumn{10}{|l|}{ Nausea \& vomiting } \\
\hline No/unknown & $2,194(72.7)$ & $94 \quad(73.4)$ & 1.00 & & 1.00 & & $64 \quad(69.6)$ & 1.00 & \\
\hline Yes & $826 \quad(27.3)$ & $34 \quad(26.6)$ & $1.02(0.69-1.51)$ & 0.92 & $1.06(0.71-1.57)$ & 0.79 & $28 \quad(30.4)$ & $1.26(0.80-1.97)$ & 0.31 \\
\hline \multicolumn{10}{|l|}{ Weight loss } \\
\hline No/unknown & $2,620(86.7)$ & $108(84.4)$ & 1.00 & & 1.00 & & $76(82.6)$ & 1.00 & \\
\hline Yes, $<5 \mathrm{~kg} /$ unknown & $205 \quad(6.8)$ & $8 \quad(6.3)$ & $1.04(0.50-2.12)$ & & $0.96(0.46-2.00)$ & & $6 \quad(6.5)$ & $1.03(0.44-2.40)$ & \\
\hline Yes, $>5 \mathrm{~kg}$ & $195 \quad(6.5)$ & 12 (9.4) & $1.81(0.99-3.28)$ & 0.08 & $1.65(0.89-3.05)$ & 0.17 & $10(10.9)$ & $2.01(1.01-3.98)$ & 0.07 \\
\hline \multicolumn{10}{|l|}{ Epigastric pain } \\
\hline No/unknown & $1,852(61.3)$ & $75 \quad(58.6)$ & 1.00 & & 1.00 & & $55 \quad(59.8)$ & 1.00 & \\
\hline Yes & $1,168(38.7)$ & $53(41.4)$ & $1.04(0.73-1.47)$ & 0.85 & $0.99(0.70-1.42)$ & 0.97 & $37(40.2)$ & $0.95(0.63-1.46)$ & 0.83 \\
\hline
\end{tabular}

GI Bleeding: Gastrointestinal bleeding.

Adjustments: age groups (16- $<40 / 40-<50 / 50-<60 / 60-<70 / 70-<80 / \geq 80$ years), sex (male/female), presence of low grade dysplasia (yes/no/unknown), income deprivation quintile (I/II/III/IV/V/unknown), Barrett's segment length (long/short or unknown), smoking status (never/former/current/unknown). 
Table 4. Endoscopic features and reported symptoms and risk of neoplastic progression at least one year after incident BE diagnosis.

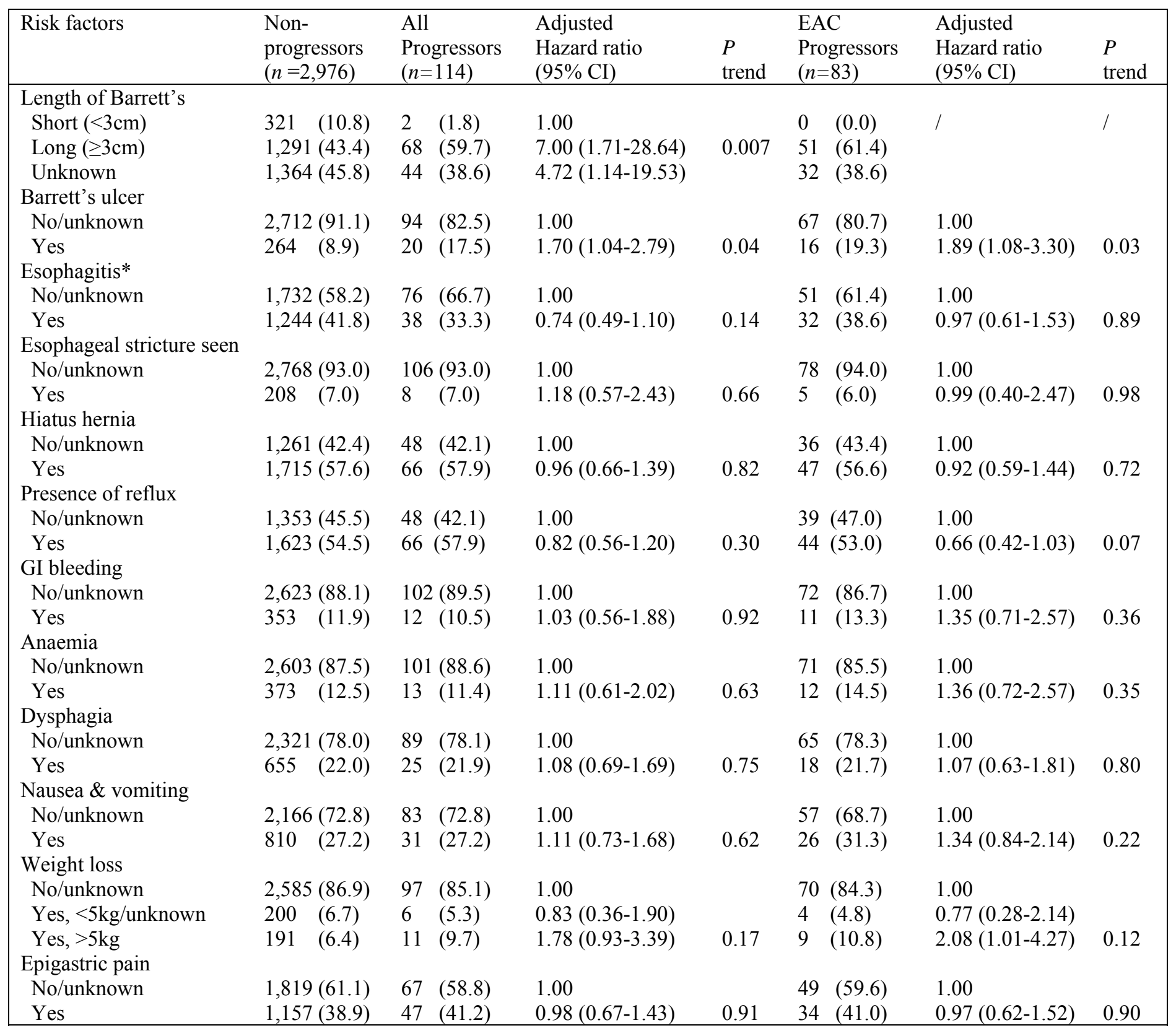

*Incorporates patients recorded as having esophagitis or ulceration in an area of the esophagus other than their Barrett's segment.

Adjustments: age groups (16- $<40 / 40-<50 / 50-<60 / 60-<70 / 70-<80 / \geq 80$ years), sex (male/female), presence of low grade dysplasia (yes/no/unknown), income deprivation quintile (I/II/III/IV/V/unknown), Barrett's segment length (long/short or unknown) (except Length of Barrett's analysis), smoking status (never/former/current/unknown). 